\title{
PENGARUH EFEKTIFITAS DAN KONTRIBUSI TERHADAP PENDAPATAN ASLI DAERAH KOTA BATAM
}

\author{
Syahril Effendi ${ }^{1^{*}}$ \\ Fakultas Ilmu Sosial dan Humaniora, Universitas Putera Batam \\ syahril@puterabatam.ac.id
}

\begin{abstract}
The development of information technology is currently growing rapidly, moreover the formation of The purpose of this study is to find answers to determine the effectiveness of parking tax and the contribution of parking tax to local revenue, where in the era of regional autonomy, local governments are required to always increase their regional revenues, such as increasing local tax revenues through billboard tax revenues. Tax revenue through advertising billboards in the city of Batam provides an undeniable contribution to regional revenue. However, in practice it has not yet come close to its true potential, besides that the preparation of this tax target is only based on previous years' experience. The length of this research was conducted from April to July 2016. The object of this research is Batam City Dispenda. The sampling technique used is non-probability sampling, namely the sampling technique using certain considerations or purposive sampling using financial reports from 2015 to 2019. The results of hypothesis testing using the multiple regression analysis method show that simultaneously the effectiveness of parking tax and the contribution of parking tax has a significant effect on local revenue. While partially the effectiveness of parking tax has a significant relationship to local revenue, however, the contribution of parking tax has a significant effect on local revenue at the Batam City Dispenda.
\end{abstract}

Keywords: Local Revenue, Parking Tax Effectiveness, Parking Tax Contribution

\section{PENDAHULUAN}

Eksistensi pembangunan daerah merupakan wujud dari keberlangsungannya pembangunan suatu negara, keberhasilan pembangunan suatu bangsa tidak terlepas dari keberhasilan daerah dalam mengelola potensi-potensi yang dimiliki oleh daerah tersebut. untuk mencapai keberhasilan pembangunan tersebut diperlukan adanya suatu kebijakan dan sistem pembangunan yang mampu memacu peningkatan kinerja sumber daya manusia dalam mengelola dan mengolah sumber daya alam yang dimiliki tiap daerah, dapat mengelola sumbersumber pendapatan daerah yang ada dan yang belum tergali agar dapat terpakai sehingga mampu meningkatkan pendapatan daerah agar lebih baik hasilnya dan dapat digunakan untuk kesejahteraan masyarakat daerah.

Pajak merupakan salah satu sumber penerimaan Pemerintah Indonesia disamping sektor migas dan ekspor barang-barang non migas yang digunakan untuk pembiayaan pembangunan dan penyelenggaraan pemerintah pusat dan pemerintah daerah, serta untuk kepentingan pembangunan nasional maupun pembangunan daerah. Dalam usaha pencapaian tujuan pembangunan tersebut, Pemerintah Pusat memberi wewenang kepada Pemerintah Daerah untuk sepenuhnya mengatur rumah tangganya sendiri termasuk dalam hal pengelolaan keuangan untuk membiayai keperluan daerah. Penarikan pajak di suatu daerah disesuaikan dengan UU Nomor 28 Tahun 2009, sesuai dengan undang-undang tersebut maka kabupaten/kota diperkenankan untuk menarik pajak daerah.

Efektifitas pajak parkir sendiri merupakan penilaian kinerja pemungutan pajak daerah yang dilakukan oleh Dinas Pendapatan Daerah selama satu tahun anggaran, apakah sudah efektif ataupun belum yang dapat dilihat dari presentase penerimaan pajak parkir yang 
direalisasikan dibandingkan dengan target yang telah ditetapkan, sedangkan kontribusi pajak parkir sendiri merupakan tingkat sumbangan pajak daerah terhadap penerimaan asli daerah yang dapat diketahui dari membandingkan penerimaan pajak parkir dengan keseluruhan pendapatan asli daerah dalam satu tahun anggaran.

Tabel 1 Data Target dan Realisasi Pajak Parkir Tahun 2015-2019 pada Dinas Pendapatan

$$
\text { Daerah Kota Batam }
$$

\begin{tabular}{|c|c|c|}
\hline Tahun & Taget & Realisai Penerimaan \\
\hline 2015 & Rp. $2000.000 .000,00$ & Rp. $2.072 .513 .815,00$ \\
\hline 2016 & Rp. $3.200 .000 .000,00$ & Rp. $3.224 .271 .163,00$ \\
\hline 2017 & Rp. $3.600 .000 .000,00$ & Rp. $3.950 .660 .588,92$ \\
\hline 2018 & Rp. $4.500 .000 .000,00$ & Rp. $4.743 .874 .393,00$ \\
\hline 2019 & Rp. $4.613 .000 .000,00$ & Rp. $4.632 .817 .812,00$ \\
\hline
\end{tabular}

Tabel 2 Data Realisasi Penerimaan PAD

\begin{tabular}{|c|c|}
\hline Tahun & Realisai Penerimaan PAD \\
\hline 2015 & Rp. $325.551 .392 .753,69$ \\
\hline 2016 & Rp. $413.178 .934 .109,31$ \\
\hline 2017 & Rp. $606.340 .450 .986,83$ \\
\hline 2018 & Rp. $779.944 .837 .450,53$ \\
\hline 2019 & Rp. $840.645 .164 .853,22$ \\
\hline
\end{tabular}

Dapat dilihat pada tabel diatas dimana setiap tahunnya Dinas Pendapatan Kota Batam selalu menaikkan target pencapaian pajak daerah yang akan dipungut. hal ini menunjukkan Kota Batam memiliki sumber-sumber yang cukup potensial yang dapat dimanfaatkan sebagai sumber Pendapatan Asli Daerah. Walaupun pada realisasinya masih ada yang belum begitu signifikan memenuhi target seperti terlihat pada tahun 2015 dan 2016 namun untuk tahun 2017, 2018 dan 2019 realisasi sudah mengalami kenaikan yang cukup signifikan dgn selalu melebihi target yang dirancangkan. Dinas Pendapatan Daerah Kota Batam selaku perangkat daerah yang bertanggungjawab atas pengelolaan Pajak Daerah perlu mengupayakan optimalisasi dalam pemungutan guna memperoleh pendapatan daerah yang cukup besar untuk pembangunan daerah Kota Batam. Besar kecilnya penerimaan pendapatan pajak daerah tergantung dari mekanisme pemungutannya.

Dari data tersebut akan bisa diketahui bagaimana efektifitas penerimaan pajak dan kontribusi pajak parkir terhadap penerimaan Pendapatan Asli Daerah, jika penerimaan pajak parkir tidak efektif makan kontribusi pajak parkir terhadap penerimaan Pendapatan Asli Daerah juga tidak akan maksimal. Berdasarkan uraian diatas tersebut, maka penulis merasa perlu untuk meneliti dan mengambil judul "Analisis Faktor-Faktor Yang Mempengaruhi Pendapatan Asli Daerah Kota Batam".

\section{TINJAUAN PUSTAKA}

\section{A. Efektifitas Pajak Parkir}

(Mahmudi, 2017: 143) menyatakan bahwa efektivitas merupakan hubungan antara keluaran dengan tujuan atau sasaran yang harus dicapai. Dikatakan efektif apabila proses kegiatan mencapai tujuan dan sasaran akhir kebijakan. Semakin besar ouput yang dihasilkan terhadap pencapaian tujuan dan sasaran yang ditentukan, maka semakin efektif proses kerja suatu unit organisasi. Dalam Peraturan Menteri Dalam Negri No. 13 Tahun 2006 tentang Pedoman Pengelolaan Keuangan Daerah, disebutkan bahwa efektifitas adalah tingkat pencapaian hasil program dengan target yang telah ditetapkan.

Pengertian-pengertian efektifitas di atas dapat disimpulkan bahwa efektifitas adalah suatu ukuran yang menyatakan seberapa jauh target (kuantitas, kualitas dan waktu) yang telah dicapai 
oleh manajemen, yang mana target tersebut sudah ditentukan terlebih dahulu. Untuk mengukur nilai efektivitas secara lebih rinci digunakan kreteria berdasarkan Kepmendagri No. 690.900.327 Tahun 1994 tentang pedoman penilaian dan kinerja keuangan yang disusun dalam tabel berikut:

Tabel 3 Rasio Efektivitas

\begin{tabular}{|c|c|}
\hline $\begin{array}{c}\text { Rasio Efektifitas } \\
(\boldsymbol{\%})\end{array}$ & Kriteria \\
\hline$>100 \%$ & Sangat Efektif \\
\hline $90 \%-100 \%$ & Efektif \\
\hline $80 \%-90 \%$ & Cukup Efektif \\
\hline $60 \%-80 \%$ & Kurang Efektif \\
\hline$<60 \%$ & Tidak Efektif \\
\hline
\end{tabular}

Sumber: Kepmendagri No. 690.900.327, Depdagri

\section{B. Kontribusi Pajak Parkir}

(Mahmudi, 2017: 145), menjelaskan bahwa kontribusi digunakan untuk mengetahui sejauh mana pajak daerah memberikan sumbangan dalam penerimaan PAD. Dalam mengetahui kontribusi dilakukan dengan membandingkan penerimaan pajak daerah periode tertentu dengan penerimaan PAD periode tertentu pula. Semakin besaar hasilnya berarti semakin besar pula peranan pajak daaerah terhadap PAD, begitu pula sebaliknya jika hasil perbandinganya terlalu kecil berarti peran pajak daerah terhadap PAD juka kecil. Sedangkan untuk mengetahui seberapa berkontribusi pajak daerah tersebut dengan asumsi sebagai berikut:

Tabel 4 Rasio Kontribusi

\begin{tabular}{|c|c|}
\hline Klasifikasi Kontribusi & Kriteria \\
\hline $0,00 \%-10 \%$ & Tidak Berkontribusi \\
\hline $10,10 \%-20 \%$ & Kurang Berkontribusi \\
\hline $20,10 \%-30 \%$ & Cukup Berkontribusi \\
\hline $30,10 \%-40 \%$ & Berkontribusi \\
\hline $40,10 \%-50 \%$ & Sangat Berkontribusi \\
\hline
\end{tabular}

Sumber : Tim Litbang Depdagri-fisipol UGM.

Kontribusi dihitung dengan membandingkan antara besarnya realisasi pajak daerah terhadap pendapatan daerah.Pajak daerah dikatakan memiliki kontribusi besar apabila hasil perhitungan lebih dari 50 persen seperti tabel diatas.

\section{Pendapatan Asli Daerah}

Menurut (Darise, 2017: 37) Pendapatan asli daerah (PAD) adalah pendapatan yang diperoleh daerah dan dipungut berdasarkan peraturan daerah sesuai dengan peraturan perundang-undangan.Pendapatan Asli Daerah yang merupakan sumber penerimaan daerah sendiri perlu terus ditingkatkan agar dapat menanggung sebagian beban belanja yang diperlukan untuk penyelenggaraan pemerintah dan kegiatan pembangunan yang setiap tahun meningkat sehingga kemandirian otonomi daearh yang luas, nyata dan bertanggung jawab dapat dilaksanakan. Dan Pendapatan Asli Daerah menurut Undang-Undang No. 28 Tahun 2009 yaitu sumber keuangan daerah yang digali dari wilayah daerah yang bersangkutan yang terdiri dari hasil pajak daerah, hasil retrubusi daaerah, hasil pengelolaan kekayaan daerah yang dipisahkan dan lain-lain pendapatan asli daerah yang sah.

\section{Kerangka Berfikir}

Kerangka pemikiran ialah penjelasan sementara terhadap gejala yang menjadi objek permasalah. Maka dari itu dapat dijelaskan bahwa objek permasalahan yang di angkat dalam penelitian ini ialah "Analisis Faktor-Faktor Yang Mempengaruhi Pendapatan Asli Daerah Kota Batam". Konsep yang telah dijelaskan tersebut dapat digambarkan seperti di bawah ini: 


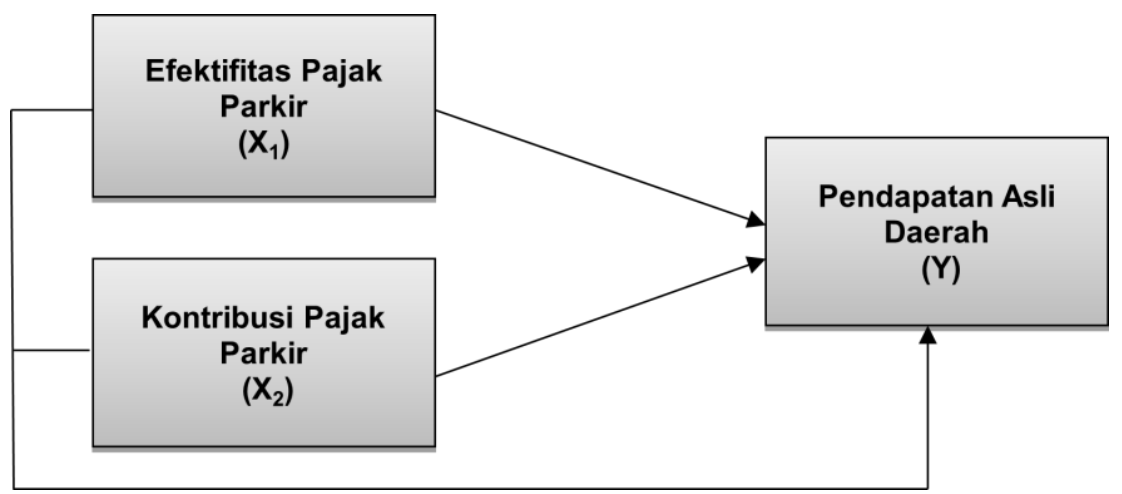

Gambar 1 Kerangka Pemikiran

\section{E. Hipotesis}

Hipotesis yang diajukan dalam penelitian ini sebagai berikut:

Hipotesis 1: Efektifitas pajak parkir berpengaruh signifikan terhadap pendapatan asli daerah Kota Batam

Hipotesis 2: Kontribusi pajak parkir berpengaruh signifikan terhadap pendapatan asli daerah Kota Batam

Hipotesis 4: Efektifitas dan kontribusi berpengaruh signifikan terhadap pendapatan asli daerah Kota Batam.

\section{METODE}

\section{A. Desain Penelitian}

Desain penelitian merupakan suatu rencana kerja yang terstruktur dalam hal hubunganhubungan antar variabel secara komprehensif, sedemkian rupa agar hasil risetnya dapat memberikan jawaban atas pertanyaan- pertanyaan riset. Dalam rencana tersebut mencakup halhal yang akan dilakukan periset mulai dari membuat hipotesis dan implikasinya secara operasional sampai pada analisis terakhir (Umar, 2017: 5).

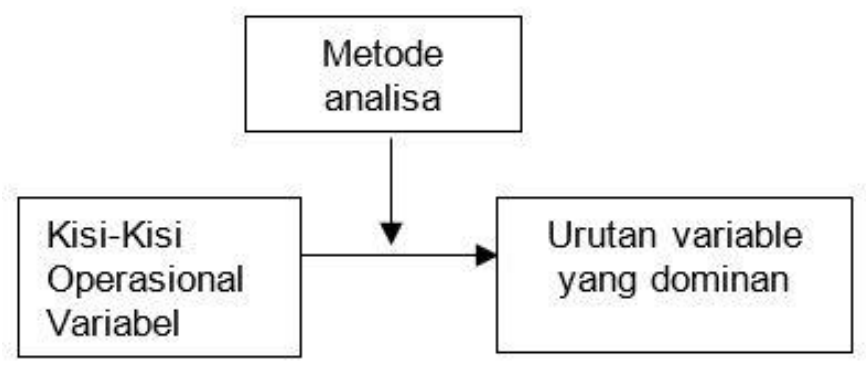

Gambar 2. Tahapan Penelitian

\section{HASIL DAN PEMBAHASAN}

Hasil penelitian merupakan ringkasan dari informasi yang diperoleh dari data dan disajikan dari bentuk uji t dan uji f.

\section{Hasil Uji t}

Digunakan untuk mengetahui pengaruh variabel independen atau bebas (X) terhadap variabel dependen atau terikat (Y). 
Tabel 3 Analisis Regresi Linier Berganda

Coefficients $^{\mathrm{a}}$

\begin{tabular}{|c|c|c|c|c|c|c|}
\hline \multirow{2}{*}{\multicolumn{2}{|c|}{ Model }} & \multicolumn{2}{|c|}{ Unstandardized Coefficients } & \multirow{2}{*}{$\begin{array}{c}\begin{array}{c}\text { Standardized } \\
\text { Coefficients }\end{array} \\
\text { Beta }\end{array}$} & \multirow[b]{2}{*}{$\mathrm{t}$} & \multirow[b]{2}{*}{ Sig. } \\
\hline & & $\mathrm{B}$ & Std. Error & & & \\
\hline \multirow[t]{3}{*}{1} & (Constant) & 264555849.952 & 99404771.646 & & 2.661 & .014 \\
\hline & Efektifitas Pajak Parkir & .278 & .082 & .415 & 3.417 & .002 \\
\hline & Kontribusi Pajak Parkir & .404 & .085 & .576 & 4.749 & .000 \\
\hline
\end{tabular}

a. Dependent Variable: Pendapatan Asli Daerah

Ada pun bentuk persamaan dari hasil perhitungan diatas adalah :

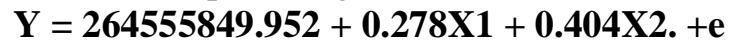

\section{Konstan $=264555849.952$}

Nilai konstanta positif menunjukkan pengaruh positif, variabel $X(X 1$ dan $X 2)$, bila variabel X (Efektifitas Pajak Parkir dan Kontribusi Pajak Parkir naik satu satuan, artinya variabel Pendapatan Asli Daerah (Y) akan mengalami kenaikan sebesar 264555849.952.

\section{Efektifitas Pajak Parkir $(\mathrm{X} 1)=0.278$}

Merupakan nilai koefisien regresi variabel Efektifitas Pajak Parkir (X1) terhadap variabel Pendapatan Asli Daerah (Y) artinya jika Efektifitas Pajak Parkir naik satu satuan, maka Pendapatan Asli Daerah (Y) akan mengalami peningkatan sebesar 0.278. Koefisien bernilai positif artinya antara Efektifitas Pajak Parkir (X1) dan Pendapatan Asli Daerah (Y) memiliki hubungan positif. Peningkatan nilai variable $\mathrm{X} 1$ akan mengakibatkan penurunan pada variable Pendapatan Asli Daerah (Y).

\section{Kontribusi Pajak Parkir $(\mathrm{X} 2)=0.404$}

Merupakan nilai koefisien regresi variabel independen Kontribusi Pajak Parkir (X2) terhadap variabel Pendapatan Asli Daerah (Y) artinya jika Kontribusi Pajak Parkir (X2) mengalami kenaikan satu satuan, maka Pendapatan Asli Daerah (Y) akan mengalami peningkatan sebesar 0.404. Koefisien bernilai positif artinya antara Kontribusi Pajak Parkir (X2) dan Pendapatan Asli Daerah (Y) memiliki hubungan positif. Peningkatan Kontribusi Pajak Parkir (X2) akan mengakibatkan peningkatan pada Pendapatan Asli Daerah (Y).

Tabel 4 Uji t

Coefficients $^{\mathrm{a}}$

\begin{tabular}{|c|c|c|c|c|c|c|}
\hline \multirow[b]{2}{*}{ Model } & & \multicolumn{2}{|c|}{ Unstandardized Coefficients } & $\begin{array}{l}\text { Standardized } \\
\text { Coefficients }\end{array}$ & \multirow[b]{2}{*}{$\mathrm{t}$} & \multirow[b]{2}{*}{ Sig. } \\
\hline & & $\mathrm{B}$ & Std. Error & Beta & & \\
\hline \multirow[t]{3}{*}{1} & (Constant) & 264555849.952 & 99404771.646 & & 2.661 & .014 \\
\hline & Efektifitas Pajak Parkir & .278 & .082 & .415 & 3.417 & .002 \\
\hline & Kontribusi Pajak Parkir & .404 & .085 & .576 & 4.749 & .000 \\
\hline
\end{tabular}

a. Dependent Variable: Pendapatan Asli Daerah

Berdasarkan tabel 2 di atas dapat dilihat nilai Efektifitas Pajak Parkir yang mempunyai nilai signifikan $0.002>0,05$. Artinya Efektifitas Pajak Parkir berpengaruh signifikan terhadap Pendapatan Asli Daerah. Hal ini menunjukkan bahwa semakin besar perusahaan maka semakin besar sumber daya yang dimiliki oleh perusahaan tersebut untuk mengelola beban pajaknya.

Hasil perhitungan dari Kontribusi Pajak Parkir mempunyai nilai signifikan $0.000>0,05$. Artinya Kontribusi Pajak Parkir berpengaruh signifikan terhadap Pendapatan Asli Daerah. Hal ini berarti semakin besar hutang maka laba kena pajak akan menjadi lebih kecil karena insentif pajak atas bunga hutang yang semakin besar. Sehingga semakin tinggi Kontribusi Pajak Parkir 
maka akan semakin rendah Pendapatan Asli Daerah yang dilakukan perusahaan karena timbulnya biaya bunga.

\section{Tabel 5 Uji F}

ANOVA $^{\text {b }}$

\begin{tabular}{|ll|c|c|c|c|c|}
\hline \multicolumn{1}{|c|}{ Model } & Sum of Squares & Df & Mean Square & F & Sig. \\
\hline 1 & Regression & 3935767668183926800 & 2 & 1967883834091963390 & $\mathbf{4 4 . 3 6 0}$ & $\mathbf{. 0 0 0}^{\mathbf{b}}$ \\
& Residual & 975963771816074370 & 67 & 44361989628003384 & & \\
Total & 4911731440000001000 & 69 & & & \\
\hline
\end{tabular}

a. Predictors: (Constant), Kontribusi Pajak Parkir, Efektifitas Pajak Parkir

b. Dependent Variable: Pendapatan Asli Daerah

Berdasarkan tabel Uji $\mathrm{F}$ diatas diperoleh nilai signifikan $0,000<0,05$ yang menunjukkan secara simultan Kontribusi Pajak Parkir dan Efektifitas Pajak Parkir, secara bersama-sama berpengaruh signifikan terhadap Pendapatan Asli Daerah (Y).

\section{SIMPULAN}

Berdasarkan hasil analisis data dan pembahasan mengenai Analisis tingkat efektifitas dan besar kontribusi pajak parkir terhadap Pendapatan Asli Daerah Kota Batam yang telah diuraikan sebelumnya, dapat disimpulkan sebagai berikut:

1. Efektifitas pajak parkir berpengaruh positif dan signifikan terhadap Pendapatan Asli Daerah di Kota Batam.

2. Kontribusi pajak parkir berpengaruh positif dan signifikan terhadap Pendapatan Asli Daerah di Kota Batam.

3. Efektifitas pajak parkir dan kontribusi pajak parkir secara bersama-sama memiliki pengaruh yang positif dan signifikan terhadap Pendapatan Asli Daerah di Kota Batam.

\section{SARAN}

Adapun rekomendasi yang dapat disarankan penulis untuk penelitian selanjutnya adalah:

1. Untuk menindak lanjuti masalah pelanggaran pajak, perlu adanya peraturan yang memuat tentang sanksi yang tegas terhadap pelanggaran pajak agar wajib pajak yang melakukan pelanggaran pajak mendapat efek jera dari perbuatan yang dilakukannya.

2. Perlu perhitungan potensi, target dan penerimaan secara dinamis dari waktu ke waktu mengingat potensi pajak parkir senantiasa berkembang seiring dengan perkembangan perekonomian daerah.

3. Dilakukan proses pengawasan terhadap wajib pajak yang sudah ada, melalui kegiatan pemantauan dan pengendalian atas seluruh proses pemungutan secara berkala.

\section{DAFTAR PUSTAKA}

Adisasmita, Rahardjo. (2017). Pengelolaan Pendapatan dan Anggaran Daerah,. Graha Ilmu, Yogyakarta.

Ghozali, Imam. (2017). Aplikasi Analisis Multivariate Dengan Program IBM SPSS 19. (Edisi Kelima.) Semarang: Universitas Diponegoro.

Halim, Abdul. (2017). Akuntansi Sektor Publik: Akuntansi Keuangan Daerah,. Salemba Empat, Jakarta.

Mardiasmo. (2017). Perpajakan Edisi Revisi, Andi Offset, Yogyakarta.

Mahmudi. (2017). Analisis Laporan Keuangan Pemerintah Daerah, UPP Sekolah. Tinggi Ilmu Manajemen YKPN, Yogyakarta. 
Nurcholis, Hanif. (2017). Teori dan Praktik Pemerintahan Dan Otonomi Daerah, PT. Grasindo,. Jakarta.

Nazir, Moh. (2014). Metode Penelitian. Cetakan Enam, Bogor: Penerbit Ghalia Indonesia.

Priyatno, Duwi. (2017). Mandiri Belajar SPSS - Bagi Mahasiswa dan Umum, Yogyakarta: Mediakom.

Resmi, Siti. (2017). Perpajakan: Teori dan Kasus. Jakarta : Salemba Empat.

Sugiyono. (2014). Metode Penelitian Kuantitatif, Kualitatif, dan Kombinasi (Mixed. Methods). Bandung: Alfabeta.

Salomo, Roy V dan M. Ikhsan. (2012). Keuangan Daerah di Indonesia. STIA LAN Press Jakarta.

Siagian, Sondang P. (2017). Administrasi Pembangunan: Konsep, Dimensi dan Strategi. Bina Aksara, Jakarta

Umar, Husein. (2017). Metode Penelitian Untuk Skripsi dan Tesis serta Bisnis. Edisi Kedua. Jakarta: Penerbit Raja

Undang-Undang No.28 tahun 2009 tentang pajak daerah dan retribusi daerah.

Undang-Undang No.33 Tahun 2004 Tentang Perimbangan Keuangan antara Pemerintah Pusat dan Pemerintah Daerah menentukan bahwa pemerintah daerah dalam pelaksanaan desentralisasi terdiri atas pendapatan daerah dan pembiayaan.

Wibowo, Agung Edy. (2012). Aplikasi Praktis SPSS Dalam Penelitian. Yogyakarta: Gava Media. 